\title{
O processo de ensino e aprendizagem de química: percepções e possibilidades diante
}

\section{do ensino remoto}

\author{
The teaching-learning process of chemistry: perceptions and possibilities regarding remote \\ teaching
}

El proceso de enseñanza y aprendizaje de química: percepciones y posibilidades ante la enseñanza

remota

Recebido: 10/11/2021 | Revisado: 16/11/2021 | Aceito: 21/11/2021 | Publicado: 29/11/2021

\author{
Talita Mendes da Costa \\ ORCID: https://orcid.org/0000-0002-9536-4952 \\ Instituto Federal do Sul de Minas Gerais, Brasil \\ E-mail: talitamc15@gmail.com \\ Nila Luciana Vilhena Madureira \\ ORCID: https://orcid.org/0000-0002-3236-9596 \\ Instituto Federal do Pará, Brasil \\ E-mail: nila.madureira@ifpa.edu.br \\ Geisa Gabrielle Santos \\ ORCID: https://orcid.org/0000-0002-8367-4339 \\ Universidade de Pernambuco, Brasil \\ E-mail: geisa.gabrielle@gmail.com \\ Pedro Paulo Ferreira Moreira \\ ORCID: https://orcid.org/0000-0002-6251-8038 \\ Universidade Federal de Ouro Preto, Brasil \\ E-mail:pedro.ferreira.moreira@educacao.mg.gov.br \\ Ivan Vilaça dos Santos \\ ORCID: https://orcid.org/0000-0001-6442-2278 \\ Faculdade Calafiori, Brasil \\ E-mail: ivanvsantos92@gmail.com
}

\begin{abstract}
Resumo
Neste período, no qual o Brasil e o mundo foram acometidos pelo vírus da COVID-19, novas propostas metodológicas surgiram e estão reorganizando o modo de ensinar e aprender Química. Alicerçado nessa realidade, este estudo objetiva compreender o ensino-aprendizagem de Química, assim como identificar as práticas metodológicas que se sobressaíram diante do contexto vivido. Para tanto, realizou-se uma revisão de literatura utilizando-se como fontes de dados os livros, artigos, monografias, teses, dissertações e trabalhos publicados em anais que abordassem de modo atual a problemática analisada. Os resultados ficaram estruturados em três tópicos, os quais abordam respectivamente sobre a caracterização do ensino-aprendizagem de Química, os processos metodológicos presentes nas práticas cotidianas, assim como a reorganização do ensino deste componente no período de pandemia. Para os dois primeiros tópicos não foi usado um recorte de tempo específico para coletar informações, isto ocorreu devido à necessidade de utilizar os principais apontamentos que constituíam a temática, independente do período. No terceiro tópico, devido à particularidade do momento vivido pela pandemia, houve a necessidade de restringir as informações coletadas, empregando trabalhos desenvolvidos entre o período de 2020 a 2021, para assim compreender como se deu o ensino de Química diante do contexto da pandemia. $\mathrm{O}$ estudo desenvolvido permitiu compreender que o ensino-aprendizagem de química deve ocorrer de modo contextualizado, contando com recursos e métodos que auxiliem na construção diária de novas concepções sobre a ciência química.
\end{abstract}

Palavras-chave: Aprendizagem; COVID-19; Ensino; Química.

\begin{abstract}
In this period, in which Brazil and the world were affected by the COVID-19 virus, new methodological proposals emerged and are reorganizing the way of using and learning Chemistry. Based on this reality, this study aims to understand the teaching-learning of Chemistry, as well as to identify the methodological practices that stood out in the context experienced. Therefore, a literature review was carried out using as data sources books, articles, monographs, theses, dissertations and works published in annals that currently addressed the analyzed problem. The results obtained are structured in three topics, which respectively address the characterization of the teaching-learning of Chemistry, the methodologies present in everyday practices, as well as the reorganization of the teaching of this component during the pandemic period. For the first two paragraphs, a specific time frame was not used for the information collected, this was due to the need to use the main notes that constituted the theme, regardless of the period. In the third topic, due to the particularity of the moment experienced by the pandemic, there was the need to restrict the information collected,
\end{abstract}


employing works developed between the period 2020 to 2021, in order to understand how the teaching of Chemistry occurred in the previous context of the pandemic. The study developed understands that the teaching-learning of chemistry must occur in a contextualized way, with resources and methods that help in the daily construction of new conceptions about chemical science.

Keywords: Learning; COVID-19; Teaching; Chemistry.

\section{Resumen}

En este período, en la cual Brasil y el mundo fueron afectados por el virus COVID-19, surgieron nuevas propuestas metodológicas y están reorganizando la forma de enseñar y aprender Química. A partir de esta realidad, este estudio tiene como objetivo comprender la enseñanza-aprendizaje de la Química, así como identificar las prácticas metodológicas que se destacaron en el contexto vivido. Por lo tanto, se realizó una revisión de la literatura utilizando como base de datos los libros, artículos, monografías, tesis, disertaciones y trabajos publicados en anales que abordaban actualmente la problemática analizada. Los resultados se estructuraron en tres temas, que abordan respectivamente la caracterización de la Química y la enseñanza-aprendizaje, los procesos metodológicos presentes en las prácticas cotidianas, así como la reorganización de la enseñanza de este componente durante el período pandémico. Para los dos primeros temas, no se utilizó un marco temporal específico para la recolección de información, esto se debió a la necesidad de utilizar las notas principales que constituyeron el tema, independientemente del período. En el tercer tema, debido a la particularidad del momento vivido por la pandemia, surgió la necesidad de restringir la información recolectada, utilizando trabajos desarrollados entre el período 2020 al 2021, con el objetivo de comprender cómo se desarrolló la enseñanza de la Química en el país delante el contexto de la pandemia. El estudio desarrollado permitió comprender que la enseñanza-aprendizaje de la química debe ocurrir de manera contextualizada, con recursos y métodos que ayuden en la construcción diaria de nuevas concepciones con respecto a la ciencia química.

Palabras clave: Aprendizaje; COVID-19; Enseñanza; Química.

\section{Introdução}

No início do ano de 2020, o mundo se viu surpreendido por uma situação de pandemia, que acometeu milhares de pessoas à contaminação pelo vírus do COVID-19, algo ainda não visto ou vivenciado ao longo do século XXI. Cidades pararam, processos produtivos refrearam as linhas de produção, escolas tiveram que interromper as suas atividades rotineiras, em suma: a humanidade teve que se recolher para tentar sobreviver ao desconhecido, uma vez que as ciências médicas ainda não sabiam como conter a velocidade da disseminação do vírus, que por onde chegava, deixava a sua marca de calamidade e destruição.

Vários continentes procuraram encontrar soluções viáveis para lidar com a situação da pandemia, todos os setores da sociedade foram afetados, dentre os quais, destacam-se as instituições de ensino, que impactadas pela necessidade de dar continuidade ao atendimento dos alunos, tiveram que criar e recriar novas formas de ensinar a aprender, uma vez que tanto professores, como alunos deveriam ser atendidos mediante ao contexto de isolamento social.

Os conteúdos das disciplinas se mantiveram, porém, a forma, como elas deveriam ser assimiladas, precisou ser ressignificada. A necessidade da mediação da aprendizagem por meio do uso dos recursos tecnológicos se tornou condição indispensável para que as aulas alcançassem a casa dos alunos, independente da região em que eles estivessem. Diante desse contexto, nunca se havia visto tantos acessos. A internet se tornou um dos principais meios de comunicação, permitindo veicular, transportar e transferir dados em escala mundial. Com isso, ampliou-se a necessidade do uso de smartphones, notebooks, recursos áudio visuais, bem como a questão da capacitação dos professores para o uso das novas ferramentas, para o planejamento e execução das atividades de ensino.

O Brasil, como os demais países do mundo, fora acometido pela pandemia causada pelo SARS-Cov-2, popularmente conhecido por COVID-19. Este vírus possui uma alta capacidade de transmissão, ocorrendo tanto pelo contato físico quanto pelo ar. Com o intuito de amenizar os impactos causados por esta variante, líderes mundiais impuseram medidas de contingência, dentre elas o distanciamento social e o fechamento dos principais locais de socialização como igrejas, instituições de ensino, fábricas e locais que não fossem de serviços essenciais (França, 2020).

Perante o caráter desafiador em que se encontrava o mundo, as instituições educacionais tiveram que formular medidas provisórias para darem assistência e continuidade ao ensino. Neste contraste, entre se proteger e desenvolver suas funções, os 
profissionais necessitaram migrar do ensino presencial para o virtual, adaptando-se à modalidade de Ensino Remoto Emergencial (ERE), desenvolvendo a partir das necessidades, novas ferramentas metodológicas que auxiliassem os discentes a compreenderem os conteúdos propostos de forma ativa e participativa por meio das Tecnologias Digitais (Silva, 2020).

O modelo de Ensino Remoto foi instaurado no sistema educacional por meio da Lei 14.040, promulgada em de 18 de agosto de 2020. De acordo com esta lei, os municípios estão liberados a se submeterem a algumas exigências, desde que “cumprida a carga horária mínima anual estabelecida nos referidos dispositivos, sem prejuízo da qualidade do ensino e da garantia dos direitos e objetivos de aprendizagem, observados" (Brasil, 2020).

Em vista das informações aqui explanadas, surge a necessidade de falar de uma das disciplinas que compõe a matriz curricular da educação básica, trata-se da Química. No ambiente escolar o estudo desta disciplina possibilita a formação e o desenvolvimento de uma concepção mais crítica do mundo, sendo capaz de investigar, adquirir habilidades e, sobretudo, utilizar o conhecimento aprendido para solucionar questões relevantes para sociedade e para a formação do ser como cidadão. Diante do exposto, este trabalho tem por intuito compreender o ensino-aprendizagem de Química, assim como identificar as práticas metodológicas que se sobressaíram diante do contexto da pandemia do COVID-19

\section{Metodologia}

Para alcançar os objetivos propostos neste trabalho, a abordagem empregada foi de caráter qualitativo, a qual visa analisar e apreender por meio do campo de análise escolhido as variáveis que o compõem (Angrosino, 2009). Para tanto, executou-se uma revisão de literatura com o intuito de evidenciar as principais percepções sobre a temática abordada. De acordo com Trentini e Paim, realizar uma revisão de literatura "significa familiarizar-se com textos e, por eles, reconhecer os autores e o que eles estudaram anteriormente sobre o problema a ser estudado" (1999, p. 68).

Neste processo foram empregados como fontes de dados, livros, artigos, monografias, teses, dissertações e trabalhos publicados em anais que abordassem de modo atual a problemática analisada. Após este levantamento, realizou-se a leitura e análise completa dos trabalhos encontrados a fim de delinear as informações que auxiliassem na compreensão do estudo. Os resultados ficaram estruturados em três tópicos para melhor abordar as percepções do ensino e aprendizagem do componente curricular química antes e durante o período da pandemia do COVID-19. Nestes, foram explanados respectivamente informações sobre a caracterização do ensino-aprendizagem de Química, desde sua introdução no ensino regular, os processos metodológicos que se perpetuaram na prática cotidiana dos docentes e sua influência na aprendizagem dos discentes, assim como a reorganização do ensino-aprendizagem deste componente curricular no período de pandemia.

Nos dois primeiros tópicos não se utilizou um recorte de tempo específico para coletar informações. Isto ocorreu devido à necessidade de utilizar os principais apontamentos que constituíam a temática, independente do período. No terceiro tópico, devido à particularidade do momento vivido pela pandemia, houve a necessidade de restringir as informações coletadas, utilizando trabalhos desenvolvidos entre o período de 2020 a 2021, para assim compreender como se deu o ensino de Química diante do contexto da pandemia.

\section{Resultados e Discussão}

\subsection{Ensino-Aprendizagem de Química}

É comum o uso dos substantivos ensino e aprendizagem (Kubo \& Botomé, 2001). Por mais que estejam diretamente relacionados, dificilmente ficam evidentes que esses termos se referem a um complexo conjunto de relações comportamentais entre educador e educando; no qual não existe ensino sem aprendizagem, podendo ocorrer em maior ou menor intensidade, ou seja, esse é um processo que ocorre mutuamente; colocando em evidência duas ações, o ato de ensinar e o ato de aprender

Para Freire (1996) ensinar não consiste na mera transferência ou acumulação de conhecimentos; ensinar é fazer pensar, 
criando ações, formulando possibilidades para sua própria formação. Ensinar é, portanto, instruir a busca pelo novo, jamais impedindo as interações ou posicionamento de cada um, respeitando sempre os saberes e a capacidade criadora do ser. Enfatizando a colocação anterior, entende-se, portanto, que aprender é uma aventura produtiva, algo muito mais benéfico que somente a mera recorrência de ações; aprender é assumir domínio sobre o conteúdo ensinado, refletindo na realidade o que foi e está sendo orientado. É a conduta de construir, reconstruir, cultivando todas as potencialidades de cada pessoa, ocasionando mudanças significativas no estilo de vida do ser.

Voltando os olhares ao ensino-aprendizagem de Química, é perceptível que a introdução deste componente é relativamente recente, visto como um integrante curricular obrigatório na educação básica brasileira foi inserido como disciplina regular a partir de 1931 (Lima, 2013). Para o progresso e a continuidade deste processo, os Parâmetros Curriculares Nacionais para o Ensino Médio (PCNEM, 1997) relatam os propósitos que devem ser almejados e atingidos pelos alunos com o ensino de Química.

Segundo os Parâmetros Curriculares Nacionais (PCN’s,1999) o aprendizado formado deve auxiliar a interpretação das mudanças químicas que acontecem no mundo físico de forma geral, assim como elaborar análises por meio de informações básicas, provenientes da cultural, dos ambientes de ensino e até mesmo da própria mídia, desenvolvendo aptidões para tomada de decisões livremente, estimulando o desenvolvimento de sujeitos críticos e conscientes (Brasil, 1999).

No ensino-aprendizagem de Química é perceptível que alguns métodos utilizados no seu desenvolvimento dão importância aos conhecimentos já adquiridos pelos alunos, considerando que estes já iniciam o processo de escolarização. Portanto, entende-se a relevância do conhecimento prévio para o melhor entendimento e assimilação a respeito de temas atinentes à vida em sociedade. Essas concepções em boa parte foram construídas e desenvolvidas nas vivências diárias, interagindo e ouvindo outras pessoas. São embasados nos conhecimentos adquiridos com os novos, os quais vão sendo produzidos e agregados à estrutura mental do indivíduo.

Em vista disso, são empregados os conhecimentos prévios dos educandos, já que a principal missão de um docente é realizada. Entretanto, há uma concordância entre os professores de Química que ministrar esta disciplina constitui um desafio complexo, o qual é fruto das diversas dimensões que compreendem a educação. Nesse sentido, na busca de aprimorar o desenvolvimento das atividades, o professor deve refletir e buscar suprir as demandas oriundas do sistema educacional, respeitando e moldando as especificidades dos indivíduos (Lima, 2017).

Assim, convicções com o decorrer do tempo foram se diversificando e desmotivando o trabalho docente. Larocca e Girardi afirmam que:

A meio caminho entre a profissionalização e a proletarização, o trabalho do professor perdeu, não apenas uma significação e status social que já vivenciou no passado, mas corre o risco de perder o sentido pessoal para o professor concretizado na satisfação que sente ao ensinar e em ir para a escola todos os dias contribuir efetivamente para o aprendizado e desenvolvimentos dos seus alunos (Larocca \& Girardi, 2011, p. 1937).

Em pleno século XXI, quando os alunos não são mais os mesmos e a sociedade também não, este ensino ainda, em alguns espaços, realiza-se com um caráter exclusivamente tradicionalista, seguindo um modelo arcaico de educação. Sendo considerada de difícil compreensão, é apontado como um ensino ligado à memorização e repetição, que se fundamenta em uma linguagem monótona, relativamente teórica e descontextualizada. Diante deste contexto, a dificuldade e a reprovação em torno desse componente é algo comum no cotidiano das escolas, tornando a assimilação uma tarefa ardilosa (Figueirêdo et al., 2019).

Conforme Albergaria (2015), Lima (2017), Fadigas e Santos (2016), é indispensável que o educador busque propiciar a desmistificação desse perfil de aprendizagem, apoiado na dificuldade, explorando meios adequados e coerentes de exercer sua profissão, usufruindo do leque de metodologias elaboradas e dispostas para facilitar o ensino. Devem-se propiciar ambientes 
benéficos à participação do aluno na aula, refletir sempre qual será a melhor maneira de se relacionar com os educandos a fim de intervir, positivamente, na construção do conhecimento químico; pois, caso contrário, o discente pode perder a motivação e, em consequência, o interesse pelo ambiente escolar.

Durante o prosseguimento da docência é importante que o professor possua autocrítica e discernimento para reconhecer e analisar o seu desempenho, cogitando melhoras futuras quanto a própria atuação (Silva et al., 2018). Em conformidade com este posicionamento, também é crucial o autodiagnóstico por parte do discente vinculado ao que ele quer se tornar, sobre o que ele pode fazer para realizar seus objetivos e onde está para poder progredir, sendo estes os pontos iniciais para a edificação de aptidões, competências e virtudes (Knowles, 1998).

Assim, os Parâmetros Curriculares Nacionais para o Ensino Médio - PCNEM ressaltam que os conteúdos abordados no ensino de Química não devem se restringir ou permanecer somente na propagação de informação, no qual não se evidencia relações contextualizadas com o cotidiano do educando, suas preferências e experiências (Brasil, 2002).

Portanto, em apoio a uma educação menos mecanizada, o Ministério da Educação alega que modificações ocorrerão apenas quando a Química estudada na educação básica for mais valorizada, desenvolvendo nas escolas um ensino no qual tenha como foco o aluno, parando de ser um mero recebedor de informações para se transformar no produtor da sua própria aprendizagem, pois a Química, como um todo, se integra como uma ferramenta primordial ao progresso cultural e educacional (Brasil, 2006).

No entanto, o entendimento dos estudantes sobre a química ao interagirem com esta disciplina no Ensino Médio apresenta-se fracionado, ou seja, para os alunos esse componente curricular é algo já pronto que precisa apenas ser conhecido e não compreendido, distorcendo o real intuito por trás da disciplina, sendo reconhecida como mais uma formalidade da educação. Outra razão que contribui para a concretização do ensino de Química é o fato dela ser demonstrada aos alunos, apenas no último ano do Ensino Fundamental, quando o convívio tardio com as informações químicas colaboram para que esses alunos adentrem no Ensino Médio com deficiências e lacunas a serem preenchidas, derivando assim questionamentos sobre o porquê ela lhes é ensinada e qual aplicação poderão fazer em suas vidas, já que é considerada como irrelevante pela maioria dos estudantes (Merçon et al., 2012).

Os empasses caracterizados referentes ao ensino e aprendizagem de Química são os mais notáveis atualmente, apesar de que se for analisar profundamente esta questão, tornam-se claros diversos outros problemas que inviabilizam uma melhoria desse ensino. Dada às circunstâncias, não é viável inferir quais práticas profissionais são mais ou menos efetivas, visto que tanto a forma clássica, quanto às metodologias contemporâneas têm um valor no desenvolvimento da aprendizagem (Teixeira et al., 2019).

\subsection{Como se aprende química}

$\mathrm{Na}$ era da informação e das modificações constantes do sujeito, estudar o processo de aprendizagem, enfatizando acertos ou erros implica em algumas variáveis. Normalmente estudantes de diferentes fases possuem posicionamentos divergentes referentes à compreensão da química, transparecendo em suas ações o gostar ou não desta ciência, tornando uma tarefa difícil de criar definições acerca da forma como cada um aprende, sem generalizar, já que se deve respeitar as particularidades de cada ser.

Mól (2017) alega que o ensino e aprendizagem de Química transitam de metodologias quantitativas e qualitativas. Isso porque não lida com coisas invariáveis como substâncias, mas com indivíduos, demandando uma melhor compreensão de que em momentos distintos os resultados podem ser variados ainda que se trabalhem com os mesmos grupos de pessoas e utilizem os mesmos métodos.

Os alunos contam com formas variadas de obter informações, o que torna desafiador efetivar a aprendizagem por parte 
dos docentes, entretanto este novo perfil de aluno implica também em um perfil diferenciado do educador (Teixeira et al., 2019), pois no perfil de mundo globalizado em que o discente está inserido é exigido que seja trabalhada e aprimorada a capacidade de observação, análise e de atuação na tomada de decisões de modo responsável (Lima, 2013). Desta forma, origina-se o impasse de que cada ser tem uma perspectiva de mundo, sendo hipocrisia crer em uma educação uniforme vindo de uma sociedade desigual e miscigenada.

Logo, devem ser considerados todos os aspectos que induzem à educação e, consequentemente, à aprendizagem, explorando individualmente a necessidade dos alunos, englobando sua autonomia, conhecimentos prévios e a relevância existente no conteúdo curricular. Dessa forma haverá garantia da interação entre o conhecimento histórico, científico, social e político (Machado, 2017).

Para Teixeira et al., (2019) compreender o porquê o indivíduo aprende ou não, é necessário analisar e assimilar o contexto em que transcorrem as práticas de aprendizado e, consequentemente, quem são os envolvidos, onde e como vivem, reconhecendo suas vivências anteriores e habilidades, ressaltando as implicações que suas emoções possuem na construção do conhecimento. Sendo o aluno ativo em seu próprio desenvolvimento e em suas próprias escolhas.

Observando o quadro educacional atual, Castro et al., (2019) relacionam as modificações existentes nos diferentes documentos oficiais que regem a educação e concluem que na prática pouca coisa mudou. Declarando ainda que na maioria das escolas ainda se vê professores com um embasamento tecnicista em seus modos diários, restringindo-se aos métodos convencionais, baseando-se em exposição e utilização do quadro.

A aplicabilidade desta metodologia não é errada se o educador souber adequar com estratégias mais inovadoras em prol da partição do estudante, expondo o teórico de forma condizente com a necessidade da sua turma e, estabelecendo relações de compartilhamento, pois a partir do momento que ocorre a inserção de estímulos e troca de informações essa aula já não é meramente receptiva.

O Programa Nacional do Livro Didático (Brasil, 2015) afirma que o livro didático de Química é o recurso mais empregado e que ocasiona maior influência no direcionamento do processo de ensino aprendizagem no ambiente educacional, sendo responsável por relacionar conceitos e referências desse campo científico, apresentando formas e metodologias supostamente possíveis de ensinar.

Teixeira et al., (2019) despertam uma percepção relevante a respeito das metodologias de ensino. Para esses autores, a Química é um componente flexível que permite o professor usufruir de várias formas para ensinar, sendo que duas ferramentas distintas são inerentes a este ensino: primeiro são as aulas teóricas que viabilizam a exposição dos conteúdos; e a segunda, são as aulas em laboratórios que permitem os alunos aplicarem em prática o que foi aprendido. Todavia, o ensino pode e deve ir além, incluindo táticas distintas das usuais como jogos pedagógicos, pesquisa, atividades lúdicas, materiais concretos e tecnologias da informação e comunicação (TIC) (Buchmann, 2016).

Nesta circunstância, Costa (2018) também reconhece a importância das diferentes abordagens no ato de ensinar, pois de acordo com a autora os discentes "gostam quando são surpreendidos pelo professor que utiliza novas práticas de ensino colocando-os a pensarem por quê é importante estudar a Química e o que ela traz de benefício para a sociedade" (2018, p.13).

Diante das diversidades metodológicas no campo educativo, os trechos a seguir foram selecionados como forma de corroborar com a singularidade no qual cada um aprende, reafirmando os posicionamentos expostos em torno da aprendizagem de Química. Informações coletadas de dois artigos distintos fazem apontamentos sobre a perspectiva dos alunos acerca do entendimento deste componente curricular.

As opiniões retiradas do trabalho de Chaves e Meotti (2019) tornam perceptível a diversidade de opiniões. Alguns demonstraram uma relação restrita às obrigações escolares, já outros, mesmo diante de tantos empecilhos, exaltaram a importância deste conteúdo. Alguns alunos justificaram que os conteúdos são difíceis e complicados, além de não estarem 
presentes na sua vida diária. Outros alegaram não possuir dificuldade, argumentando que a disciplina é interessante e que o professor explica bem os conteúdos apesar de exigir muita atenção.

A aprendizagem de Química descrita no trabalho mencionado anteriormente, para muitos alunos, é algo mecânico simplesmente reprodutivo, enquanto para outros assume caráter produtivo, no qual o sujeito pode e é ativo no seu desenvolvimento. Quando ele prioriza o conhecimento que pode ser adquirido mesmo com adversidades e sabe que por meio dele pode resolver alguma necessidade ou problema, aproxima-se do raciocínio da distinção de aprendizagem feita por Ausubel et al. (1978) entre a tendência de aprender de forma mecânica adquirindo o conhecimento de forma arbitrária ou aprender de maneira significativa agregando o conhecimento desenvolvendo seu cognitivo.

Buchmann (2016) admite que os alunos aprenderam e demonstraram mais interesse com as aulas ministradas com alguma das metodologias não tradicionais. Demonstrando essa perspectiva na prática, a segunda pesquisa analisada evidencia uma prática educacional não muito distante da realidade, no qual Silva et al. (2017) desenvolveram um trabalho colocando os alunos diante de metodologias distintas, analisando a aprendizagem e a influência das mudanças motivacionais.

Das metodologias propostas, os alunos consideraram a aula prática um modo ativo de aprender com mais facilidade, afirmaram também que os jogos tornam a aula interativa e divertida de se resolver os exercícios propostos, favorecendo o aprendizado. Inclusive uma quantidade considerável de alunos gostaria que os outros professores também adotassem essas metodologias diferenciadas e inovadoras. Desta forma, os educandos consideram que durante as aulas foi possível adquirir bom conhecimento no assunto.

Uma pequena parte alegou apenas gostar das aulas, considerando-as legais. Isto ocorreu devido ao menor comprometimento em relação aos demais, mostrando que os propósitos de cada um também interferem neste processo, reforçando a ideia e a necessidade de que intervir no aumento do interesse do aluno nas aulas de Química é uma necessidade. Segundo os autores Silva et al., (2017) os alunos revelaram resultados favoráveis diante das situações propostas. A abordagem da química por meio de metodologias como experimentação, jogos, entre outras, promoveu uma aprendizagem mais eficaz provocando maior interesse, motivação individual e coletiva causando mudanças nítidas nas atitudes dos alunos, motivando-os nos estudos em casa também. Pôde-se perceber o entusiasmo e a felicidade de cada um, ao participar e superar uma tarefa, tornando todo o desenvolver das atividades algo motivador ao estudo.

Em vista disso, a motivação e afinidade do aluno para querer aprender Química surgem como uma criação abstrata resultante da relação escolar e das vivências extraescolares de cada um. Deste modo, aprender Química está associado aos diversos fatores, desde uma aula que provocou uma aprendizagem significativa independente da metodologia, até a imagem representada por um professor, já que quando se tem interesse por uma determinada área há um maior incentivo gerando melhoras na aprendizagem (Machado, 2017).

\subsection{COVID-19, Ensino Remoto Emergencial e Ensino de Química}

No final de 2019, foi confirmado em Wuhan, na China, o primeiro caso de infecção causada pelo vírus Sars-Cov-2, popularmente conhecido como COVID-19. Devido ao alto poder de contágio, a doença circulou rapidamente pelo mundo, passando pela Europa e logo em seguida, em fevereiro de 2020 acometeu a população brasileira. Perante às circunstâncias vivenciadas, líderes mundiais com o intuito de conter a disseminação do vírus impuseram medidas protetivas, dentre as quais a higiene frequente das mãos, o uso de máscara e álcool 70\%, assim como o distanciamento social (Bezerra et al., 2020), com isto, locais com grande circulação de pessoas foram orientados a fechar.

Devido à pandemia, as instituições de ensino rapidamente puseram em prática as medidas impostas pelos gestores da saúde pública, suspendendo as aulas presenciais, modificando drasticamente a forma de desenvolver e disseminar a educação, contando especialmente com os recursos digitais disponíveis. Das instituições públicas a privadas, docentes, discentes e os 
demais colaboradores ficaram expostos às incertezas do momento vivido. Diante disto, foi elaborada uma modalidade provisória de ensino na qual incentivava a oferta das aulas de forma remota para aqueles locais que em o Projeto Político Pedagógico não incluíam o ensino online, este foi denominado Ensino Remoto Emergencial (Yamaguchi, 2021).

O Ensino Remoto Emergencial (ERE) é o modelo de escolarização que utiliza a tecnologia atrelada aos instrumentos educacionais. Ainda que estejam diretamente vinculados ao uso da tecnologia, cabe evidenciar que há diferenças entre ensino remoto e ensino a distância (EAD), já que esta última modalidade tem um roteiro metodológico específico, além de materiais, fóruns de debates e tutores especializados para tal finalidade (Morais et al., 2020).

Mesmo em uma sociedade globalizada, as tecnologias da informação e comunicação não estavam presentes no cotidiano escolar, com isto, as mudanças abruptas no ensino realçaram a ausência de tais recursos, assim como o despreparo para manuseálos. Para Yamaguchi (2021) foi de extrema importante a adesão do ensino remoto, mesmo que os envolvidos não estivessem preparados para alterações repentinas, as modificações vividas auxiliaram na reflexão sobre o conceito de ensino na era digital, bem como instigaram uma participação mais ativa das tecnologias e dos principais idealizadores do processo de ensinoaprendizagem, alunos e professores.

Mesmo antes da pandemia, o ensino de química já era caracterizado como metódico e difícil compreensão, demandando maior atenção e dedicação na sua compreensão, visto que em sua grande maioria é constituído por fórmulas e conceitos abstratos. Trazendo essa concepção para o ambiente virtual, percebe-se que ministrar esta disciplina à distância requer maior foco, empenho e discernimento no decorrer das aulas (Sales et al., 2020), bem como, exige maiores preocupações sobre o acesso às ferramentas como internet e os equipamentos eletrônicos indispensáveis para que o ensino ocorra (Sousa \& Valério, 2021).

A ação docente, nesta fase de adaptação à educação remota, é desafiadora, desenvolver um ambiente inclusivo, reinventar-se diariamente na elaboração de materiais pedagógicos, metodologias didáticas e diferenciadas, gravação e edição de aulas impõe ao educador uma conduta de instrutor e simultaneamente de aprendiz, visto "quem ensina aprende ao ensinar e quem aprende ensina ao aprender" (Freire, 1996, p.17).

Existe uma diversidade de ferramentas tecnológicas que podem ser utilizadas para fins educacionais. Cada instituição de ensino, de acordo com seu público-alvo, adotou plataformas digitais com o intuito de minimizar os impactos da pandemia e darem continuidade ao ensino, dentre elas estão: Zoom, Google Classroom, Google Meet, Moodle, Microsoft Teams, YouTube e WhatsApp (Corrêa \& Brandemberg, 2021; Machado,2020). Ainda que tradicionalmente o uso de redes sociais não esteja disposto no protocolo pedagógico, neste período de pandemia seu uso foi de grande valia, devido ao distanciamento social, utilizar os aplicativos de comunicação auxiliou o contato direto entre professores, alunos e suas famílias (Santos \& Ferreira, 2021).

Outrossim, cabe salientar que devido à falta de acesso ou familiaridade com a tecnologia, houve escolas que optaram em conceder materiais impressos, objetivando atender a um maior número de discentes (Machado,2020).

Ainda que não seja possível mensurar o total impacto da pandemia do COVID-19 no ensino Química, percebe-se, pelos estudos já desenvolvidos, que este cenário educacional apresenta pontos positivos e negativos. Se por um lado, as aulas ministradas virtualmente indicam que é possível inovar e despertar o interesse dos discentes, diversificando as maneiras de aprender com uma linguagem contextualizada e autônoma (Santos \& Ferreira, 2021) por meio de vídeos, simuladores de experimentos e redes sociais. Por outro, as dificuldades de acessibilidade (Santos \& Ferreira, 2021), restrições nas interações e diálogos entre os alunos no momento das aulas, seja por fragilidade dos recursos disponíveis ou até mesmo por timidez (Cunha et al., 2020) em conjunto com o aumento da evasão escolar (Senhoras, 2020) revelaram-se desafios presentes nas aulas de Química. 


\section{Conclusão}

O estudo desenvolvido permitiu compreender que o ensino de química não pode ser reduzido a um caráter transmissivo e metódico dos conteúdos pré-determinados pelos currículos educacionais. O ensino deste componente transcende os limites físicos das instituições de ensino e está ligado às práticas cotidianas, com isto as ações a serem desenvolvidas para efetivarem a aprendizagem deste componente devem ocorrer de modo contextualizado, coerente e inovador (Costa, 2018).

O ensino de Química, do mesmo modo como os demais componentes curriculares, neste período pandêmico, teve que passar por adaptações significativas. Devido ao distanciamento social, adotou-se a modalidade de ensino ERE (Ensino Remoto Emergencial) para que os discentes não perdessem os vínculos com as instituições de ensino e assim pudessem dar seguimento aos estudos por meio dos recursos tecnológicos. Com isto, para não comprometer a aprendizagem dos discentes, os profissionais necessitaram ressignificar o seu jeito de ser e se fazer docente.

Neste cenário adverso que a pandemia do covid-19 impôs, fica evidente a imprescindibilidade do uso das Tecnologias da informação e comunicação como ferramenta transformadora do ensino de modo contextualizado e interdisciplinar. Entretanto, alguns pontos devem ser elencados, se por um lado os recursos oferecidos pelo ambiente virtual favoreceram a dinamicidade no processo de ensino-aprendizagem confirmando o que estudos anteriores já haviam afirmado sobre esta ferramenta (Buchmann, 2016; Costa, 2018), por outro evidenciou com maior veemência as disparidades sociais, econômicas e educacionais (Cunha et al., 2020; Senhoras, 2020; Santos \& Ferreira, 2021). Tais disparidades demandam maiores atenções e ações efetivas para um ensino mais igualitário no pós-pandemia.

Este trabalho, portanto, abre espaços para reflexões em prol de melhoras no processo de ensino e aprendizagem, por estimular o conhecimento sobre as políticas educacionais e os métodos de ensino, viabiliza visões amplas do que se espera e, consequentemente, do que se pode fazer para melhor efetivação do ensino de Química. Ademais, devido às incertezas dos momentos vividos, o desenvolver deste componente gera inquietações. Deste modo, espera-se que por meio das informações aqui expostas, este estudo auxilie em uma maior propagação de conhecimentos referente a temática, assim como, instigue os demais profissionais a pesquisarem, pelo fato que ainda há um longo percurso a traçar, até se compreender de fato a influência da pandemia do COVID-19 na educação.

\section{Referências}

Albergaria, M. B. (2015). Caracterização das principais dificuldades de aprendizagem em química de alunos da $1^{\circ}$ série do ensino médio. Novembro de 2015. 14f. Trabalho de Conclusão de Curso (Graduação em Ciências Naturais) - Setor de Ciências Naturais, Universidade de Brasília. https://bdm.unb.br/bitstream/10483/13838/1/2015_MayaraBezerradeAlbergaria.pdf.

Angrosino, M. (2009). Etnografia e observação participante. Artmed.

Ausubel, D. P., Novak, J. D \& Hanesian, H. (1978) Educational psychology: a cognitive view. (2a ed.), Holt, Rinehart e Winston, p.733.

Bezerra, A. C. V., Silva, C. E. M, Soares, F. G, Silva \& J. A. M. (2020) Fatores associados ao comportamento da população durante o isolamento social na pandemia de COVID-19. Ciência \& Saúde Coletiva, 25, 2411-2421, 05. UNIFESP (SciELO) https://www.scielo.br/j/csc/a/9g4hLHkSSW35gYsSpggz6rn/?lang=pt\#

Brasil, Ministério de Educação e Cultura. (2020). Parâmetros Curriculares Nacionais para o Ensino Médio. Química $-1^{\circ}$ ao $3^{\circ}$ ano. Brasília, SEF. http://portal.mec.gov.br/seb/arquivos/pdf/ciencian.pdf.

Brasil, Ministério da Educação e Cultura. Secretaria de Educação Básica (SEB). (2006) Orientações curriculares para o ensino médio: ciências da natureza, matemática e suas tecnologias. Brasília, DF: MEC/SEB. http://portal.mec.gov.br/seb/arquivos/pdf/book_volume_02_internet.pdf.

Brasil, Ministério da Educação e Cultura. Secretaria de Educação Média e Tecnológica. (SEMTEC). (2006) PCN+ ensino médio: orientações educacionais complementares aos Parâmetros Curriculares Nacionais: ciências da natureza, matemática e suas tecnologias. Brasília, DF: MEC/SEMTEC.http://portal.mec.gov.br/seb/arquivos/pdf/CienciasNatureza.pdf.

Brasil, Ministério da Educação e Cultura. Secretaria de Educação Média e Tecnológica. (SEMTEC). (1999) Parâmetros curriculares nacionais: Ensino Médio. Brasília: MEC/SEMTEC. http://portal.mec.gov.br/setec/arquivos/pdf/BasesLegais.pdf.

Brasil. Ministério da Educação e Cultura. (2020) Secretaria de Educação Básica (SEB). Guia de livros didáticos: PNLD: Química. Brasília. http://www.fnde.gov.br/phocadownload/programas/Livro_Didatico_PNLD/Guias/PNLD_2015/pnld_2015_quimica.pdf. 
Brasil. Lei $n^{\circ}$ 14.040, de 18 de agosto de 2020. (2020) Estabelece normas educacionais excepcionais a serem adotadas durante o estado de calamidade pública reconhecido pelo Decreto Legislativo ${ }^{\circ}$ 6, de 20 de março de 2020; e altera a Lei $n^{\circ} 11.947$, de 16 de junho de 2009 . Diário Oficial da União. Publicado em: 19/08/2020, Edição 159, Seção 1, Página 4. http://www.planalto.gov.br/ccivil_03/_ato20192022/2020/lei/L14040.htm.

Buchmann, J. (2016). Aplicação de diferentes metodologias e análise do processo de ensino/aprendizagem em química em escolas públicas do interior do estado do Rio Grande do Sul. 100 f. Dissertação (Mestrado Profissional no Curso de Ensino de Ciências e Matemática), Programa de Pós-Graduação em Ensino de Ciências e Matemática, Universidade Luterana do Brasil, Canoas. http://www.ppgecim.ulbra.br/teses/index.php/ppgecim/article/view/287.

Castro, E. A., Paiva, F. M. \& Silva, A.M. (2019). Aprendizagem em química: desafios na educação básica. Revista Nova Paideia - Revista Interdisciplinar em Educação e Pesquisa, 1(1), 73-88. 10.36732/riep.v1i1.15. https://ojs.novapaideia.org/index.php/RIEP/article/view/15.

Chaves, J. F., \& Meotti, P. R. M. (2019) Dificuldades no Ensino Aprendizagem e Estratégias Motivacionais na Disciplina de Química no Instituto Federal do Amazonas- Campus Humaitá. Revista Educamazônia, 22(1), 206- 224 https://periodicos.ufam.edu.br/index.php/educamazonia/article/view/5771.

Corrêa, J. N., P., \& Brandemberg, J.C. (2020). Tecnologias digitais da informação e comunicação no ensino de matemática em tempos de pandemia: desafios e possibilidades. Boletim Cearense de Educação e História da Matemática, 8(22), 34- 54.https://revistas.uece.br/index.php/BOCEHM/article/view/4176.

Costa, A. V. S. (2018) Um Estudo sobre a formação e atuação dos professores de Química do Município da Serra do Mel / RN. 72 f. Trabalho de Conclusão de Curso (Especialização Interdisciplinar em Educação do Campo), Centro de Ciencias Sociais, Aplicadas e Humanas, Universidade Federal Rural do Semiárido: Ufersa, Mossoró. https://repositorio.ufersa.edu.br/bitstream/prefix/3311/2/AntoniaVSC_MONO.pdf.

Cunha, L. F. F, Silva, A.S \&Silva, A. P. (2020). O ensino remoto no Brasil em tempos de pandemia: diálogos acerca da qualidade e do direito e acesso à educação. Revista Com Censo: Estudos Educacionais do Distrito Federal, 7(3), 27-37. http://periodicos.se.df.gov.br/index.php/comcenso/article/view/924

Fadigas, J. C., \& Santos, N. O. (2016). A didática na formação inicial de professores de Química. In: FADIGAS, J. C., SANTOS, N. O. Professores de química em formação: contribuições para um ensino significativo. Cruz das Almas/BA: UFRB. p. 19-56.

Figueirêdo, A. M.T. A., Lima, J. S., Araújo, V. M. S., Sales, F. R. P, \& Tavares, M. J. F. (2020) Utilização de ferramentas didáticas no ensino de Química visando aprimorar o processo de ensino- aprendizagem. IJET-PDVL. 208-221. https://ijet-pdvl.com/index.php/pdvl/article/view/84/14. FRANÇA, A. Coronavírus chega ao Brasil. Isto é. https://istoe.com.br/coronavirus-chega-ao-brasil/.

Freire, P. (1996). Pedagogia da autonomia: Saberes Necessários à Prática Educativa. (25a ed.), Paz e Terra- Coleção Leitura, p.54.

Knowles, M. S. (1998). The adult learner: the definitive classic in adult education and human resource development. San Diego: Elsevier ButterworthHeinemann, p.195.

Kubo, O., \& Botomé, S. P. (2001). Ensino-aprendizagem: uma interação entre dois processos comportamentais. Interação, Curitiba, (5), 123-132. https://revistas.ufpr.br/psicologia/article/view/3321.

Larocca, P., \& Girardi, P.G. (2011). Trabalho, satisfação e motivação docente: um estudo exploratório com professores da educação básica. In: X CONGRESSO NACIONAL DE EDUCAÇÃO (EDUCERE), 10,, 2011, Curitiba. Anais eletrônicos. Curitiba: PUC-PR. 19321948.https://educere.bruc.com.br/CD2011/pdf/5429_2605.pdf.

Lima, J. A. (2017). Contextualização e ensino de Química na educação básica: Uma estratégia para promoção de aprendizagem significativa. Revista Docentes, Ceará, p.39- 49. https://revistadocentes.seduc.ce.gov.br/index.php/revistadocentes/article/view/77.

Lima, M. E. C. C, \& Silva, N. S. A. (2012). Química no Ensino Fundamental: uma proposta em ação. In: Zanon, L.B, Maldaner, O. (org.). Fundamentos e propostas de ensino de química para a educação básica no Brasil. Ijuí: UNIJUÍ, p. 89-107.

Machado, M. A.S. (2017). A Percepção dos alunos sobre o ensino de ciências naturais. 35 f. Trabalho de Conclusão de Curso (Especialização em Ciências Naturais), Departamento de Ciencias Naturais, Bniversidade de Brasília, https://bdm.unb.br/bitstream/10483/18181/1/2017_MariaAmandaDaSilva_tcc.pdf.

Machado, P. L. P. (2020). Educação em tempos de pandemia: O ensinar através de tecnologias e mídias digitais. Revista Científica Multidisciplinar Núcleo do Conhecimento. Ano 05, 8, 58-68. https://www.nucleodoconhecimento.com.br/educacao/tempos-de-pandemia.

Merçon, F., Souza, M.P, Valadares, C. M., S., Pereira, J. A.S, Silva, J. A, \& Conceição, R. E. (2012). Estratégias didáticas no ensino de química. e-MosaicosRevista Multidisciplinar De Ensino, Pesquisa, Extensão E Cultura Do Instituto De Aplicação Fernando Rodrigues Da Silveira (CAP-UERJ), 1(1), 79-93. https://www.e-publicacoes.uerj.br/index.php/e-mosaicos/article/view/4386.

Mól, G. S. (2017). Pesquisa Qualitativa em Ensino de Química. Revista Pesquisa Qualitativa. 5(9), 495-513. https://editora.sepq.org.br/rpq/article/view/140.

Morais, I. R. D., Garcia, T. C. M., Rêgo, M. C. F. D., Zaros, L. G., \& Gomes, A.V. (2020). Ensino remoto emergencial: orientações básicas para elaboração do plano de aula. 2020. 24 f. Monografia (Especialização) - Curso de Educação à Distância, SEDIS-UFRN, Universidade Federal do Rio Grande do Norte, Natal.https://repositorio.ufrn.br.

Sales, P. F. (2020). "Químiemcasa”: aspectos de um processo de ensino para a aprendizagem de Química em épocas de pandemia. Research, Society and Development, 9(11), 1-19https://redib.org/Record/oai_articulo3007428-\%E2\%80\%9Cqu\%C3\%ADmiemcasa\%E2\%80\%9D-aspectos-de-um-processo-deensino-para-a-aprendizagem-de-qu\%C3\%ADmica-em-\%C3\%A9pocas-de-pandemia.

Santos, J. R., \& Ferreira, M. E. (2021). A report of teaching chemistry in the context of the pandemic of COVID-19 in the public network of São Paulo: The challenge of virtual classes in Basic Education. Research, Society and Development, 10(2), e8710212267. $10.33448 / \mathrm{rsd}-\mathrm{v} 10 \mathrm{i} 2.12267$. https://rsdjournal.org/index.php/rsd/article/view/12267.

Senhoras, E. M. (2021). Coronavírus E Educação: Análise Dos Impactos Assimétricos. Boletim de Conjuntura (BOCA), 2(5), 128-136. https://revista.ufrr.br/boca/article/view/Covid-19Educacao. 
Silva, D.A. (2020). Termoensino: uma proposta para o ensino de termoquímica com experimentos e produção de vídeos. 139f. Dissertação (Mestrado Profissional em Química - Profqui) - Centro de Ciências Exatas e da Terra, Universidade Federal do Rio Grande do Norte, Natal, 2020. https://repositorio.ufrn.br/handle/123456789/31823.

Silva, F., Sales, L. L.M, \& Silva, M. N. (2019). O uso de metodologias alternativas no ensino de química: um estudo de caso com discentes do $1^{\circ}$ ano do ensino médio no município de Rajazeiras-PB. Revista de 2. https://cfp.revistas.ufcg.edu.br/cfp/index.php/pesquisainterdisciplinar/article/view/372.

Silva, S. G. (2013). As principais dificuldades na aprendizagem de química na visão dos alunos do ensino médio. IX Congic, 1612-1616, http://www2.ifrn.edu.br/ocs/index.php/congic/ix/paper/viewFile/1037/76.

Silva, T. A. F., Lopes, L. A., Oliveira, M.V., Costa, H. P. S., Magalhães, F. E. A., Guedes, M. I. F., Moura \& L. F. W. G. (2018). Escolas públicas e privadas em Tauá-CE: Como anda o ensino de Química? Cadernos de Cultura e Ciencias, 17(2),.1-12, http://periodicos.urca.br/ojs/index.php/cadernos/article/view/1697.

Sousa, L. G., \& Valério, R. B. R. Química experimental no ensino remoto em tempos de Covid-19. (2021). Ensino em Perspectivas, 2(4), 1-10. https://revistas.uece.br/index.php/ensinoemperspectivas/article/view/6652.

Teixeira, V. M. M. de L., Santos, A. R. \& Graebner, I. B. (2019). O docente de química e a busca do fazer diferente: um estudo sobre as formas alternativas para ensinar. Scientia Naturalis, 1(3), 250-264.

Trentini, M., \& Paim, L. (1999). Pesquisa em Enfermagem: uma modalidade convergente-assistencial. Editora da UFSC.

Yamaguchi, K. K. L. (2021). Ensino de química inorgânica mediada pelo uso das tecnologias digitais no período de ensino remoto. Revista Prática Docente, 6(2). http://doi.org/10.23926/RPD.2021.v6.n2.e041.id998. 